\title{
To mature or not to mature: The information systems conun- drum
}

\author{
Carl Marnewick
}

Applied Information Systems, University of Johannesburg, South Africa

\begin{abstract}
Research has been done within the South African information technology (IT) industry over the last decade with regard to project management maturity (PMM) and the impact it has on delivering information systems (IS) projects successfully. The research was done to determine whether IS PMM per knowledge area has improved over the last decade. It investigates if there is a correlation between maturity levels and project success. Four independent surveys over the last decade focused on IS PMM and the longitudinal analysis provides a benchmark for whether IS PMM has increased or not. This article focuses on whether certain knowledge areas are more of a problem within the IT industry and to determine what the overall IS PMM is. The longitudinal analysis indicates trends and highlights areas of concern. It indicates that most IT companies are still operating at level 3 and that risk and procurement management are the knowledge areas of concern. A comparative analysis indicates that there is no difference between South African and international maturity levels. The results provide a South African perspective of IS PMM. It highlights that risk management is still a knowledge area that is neglected and that emphasis must be placed on managing risk within IT projects.
\end{abstract}

KEYWORDS: information systems, longitudinal analysis, maturity levels, project success

CATEGORIES: K.6.1

\section{INTRODUCTION}

The origins of project management maturity (PMM) stem from the Capability Maturity Model Integration (CMMI) maturity model of Carnegie Mellon's Software Engineering Institute and are thus deeply rooted within the information systems (IS) discipline. If this is the case, then we must ask why is it that the maturity of IS projects is still significantly low and has not advanced over the last twenty years. IS-related projects within the South African sphere are still perceived as failures. Extensive research over the last decade has indicated that the project success rate has risen from $43 \%$ to $59 \%$ 1]. This $16 \%$ increase cannot be attributed to the actual improvement of IS project management, but more to the way in which success is measured 1] 2]. The purpose of this article is to determine whether mature IS project management processes can and will contribute to the overall IS project success rate.

Research on IS project success and maturity has focused more on IS project success and not necessarily on IS PMM. The problem that stems from previous research is that there are no in-depth analyses of IS PMM within the South African context and its relation to IS project success. That research scratched the surface of IS PMM and did not provide the necessary indepth analysis needed to improve the success rates of IS

Email: Carl Marnewick cmarnewick@uj.ac.za projects. An in-depth analysis of IS PMM's significance cannot be underestimated. An understanding of IS PMM contributes to the following:

a. identification of maturity gaps within the IS PMM processes,

b. the relation between IS PMM and IS project success, and

c. possible competencies that might address IS PMM.

Research on PMM has come a long way. Various authors have researched PMM and covered a wide range of aspects ranging from the maturity of project management in different industries [3] to the impact of PMM on mega-construction programmes in China [4. The claim was investigated that an organisation's PMM leads to competitive advantage [5]. Research was also done to benchmark PMM across various industries and sectors 6] 7]. Postgraduate students at universities across the globe also spend time analysing and researching PMM [8]. Despite all this international research, research in PMM seems to be neglected in the South African context. The last couple of years have seen the publication of a small amount of research 9] 10]. This research has provided PMM benchmarks in the engineering and construction industries as well as an African perspective of PMM across all industries.

This article addresses IS PMM within the South African context and focuses on the relationship between IS PMM and project success. No comparison has been made previously to international studies to determine 
whether the maturity of IS projects is worse off in South Africa than in the rest of the world. This research contributes to the overall IS PMM body of knowledge and specifically which project management knowledge areas must be addressed by organisations to ensure project success.

Quantitative analysis is used to measure the IS PMM within organisations. This quantitative analysis is done through a longitudinal study based on data collected since 2003 at periodical intervals. The data was collected through self-administered structured questionnaires.

The article comprises the following sections: the first section provides an overview of IS PMM within the context of organisational maturity. The second section focuses on the research methodology used and this is followed by an in-depth analysis of the results. Descriptive analysis as well as inferential analysis is used to shed some light on the results. The fourth section concludes the article with some insight on the relation between the project management knowledge areas and project success.

\section{LITERATURE REVIEW}

There is general consensus that PMM originated from the Software Engineering Institute's Capability Maturity Model [3] 7] 8]. From these beginnings in software development process maturity, various PMM models used to measure project maturity were developed by various organisations and researchers. Two of these organisations are the Project Management Institute [11] and the Office of Government Commerce [12.

Against this backdrop of various models and research initiatives on PMM, the question that needs to be answered is: What is organisational maturity and how does it influence PMM and specifically IS PMM? Organisational maturity can be defined as "the extent to which an organisation has explicitly and consistently deployed processes that are documented, managed, measured, controlled and continually improved" [13. The implication is that organisational maturity varies within an organisation itself as well as from organisation to organisation. Organisational maturity is phrased as "a state where the organisation is in such a perfect condition that it achieves all of its objectives" 14. Organisational maturity itself also depends on processes and the maturity of these processes. The logical connection was made between PMM and the capability of project management for the organisation [8]. Well-defined, repeatable and predictable project management processes contribute to the maturity of project management capability 7 . Seven factors were identified contributing to project management capability [15. Two of these seven factors are important for this research, i.e.

a. the project management processes themselves, and

b. IS which assists with the integration and dissemination of the outputs of all the projects studied [16].
Table 1: Capability maturity levels and descriptions

\begin{tabular}{|c|c|}
\hline Maturity levels & Description \\
\hline Level 1: Ad hoc & $\begin{array}{l}\text { Ad hoc and occasionally } \\
\text { chaotic }\end{array}$ \\
\hline Level 2: & Basic project management \\
\hline Repeatable & $\begin{array}{l}\text { A process discipline is in } \\
\text { place to repeat earlier suc- } \\
\text { cesses }\end{array}$ \\
\hline \multirow[t]{3}{*}{ Level 3: Defined } & Includes Level 2 \\
\hline & $\begin{array}{l}\text { Software processes are stan- } \\
\text { dardized and integrated }\end{array}$ \\
\hline & $\begin{array}{l}\text { Projects use these approved } \\
\text { processes }\end{array}$ \\
\hline \multirow[t]{2}{*}{ Level 4: Managed } & Includes Level 3 \\
\hline & $\begin{array}{l}\text { Detailed metrics of software } \\
\text { product and processes are col- } \\
\text { lected } \\
\text { Software processes and prod- } \\
\text { uct controlled using these } \\
\text { metrics }\end{array}$ \\
\hline \multirow[t]{2}{*}{ Level 5: Optimised } & Includes Level 4 \\
\hline & $\begin{array}{l}\text { Continuous process improve- } \\
\text { ments enabled by quantita- } \\
\text { tive feedback } \\
\text { Innovative ideas and tech- } \\
\text { nologies developed based on } \\
\text { feedback }\end{array}$ \\
\hline
\end{tabular}

The first factor, project management processes, is dealt with in PMM which refers to the progressive development of an enterprise-wide project management approach, methodology, strategy and decision-making process 14. The project management processes are covered through the various PMM models. These models have become an essential tool to evaluate the maturity of the project management processes themselves. Various PMM models focus on measuring and improving the project management processes. One of the most used and referenced models is that of the PMI, i.e. the Organizational Project Management Maturity Model (OPM3). The focus of the OPM3 is to (i) assess the maturity of each process based on the current institutional knowledge and then to (ii) improve the maturity of the processes. The improvement is based on the capabilities that the organisation has and does not have. This is a continuous process where the organisation returns to assess and improve the project management processes.

The second factor is information systems, which play a role in the capability of the organisation. The maturity model mostly used in IS, is the Software Engineering Institute's Capability Maturity Model (CMM). The model involves five linear stages ranging from level 1 , where the processes are ad hoc, to level 5 , where the processes are optimised in an adaptive and sustained manner 13 .

The problem is that the CMM focuses on software engineering and not necessarily on IS. It can be deduced from the above that the successful implementation of IS must be done through mature project management as well as software engineering processes.

The obvious benefit is an improved project success rate for IS projects, but this alone should not be the only motivation to improve the maturity levels. Higher 
levels of PMM levels are associated with better cost and schedule performance [17. This observation itself should encourage organisations to pursue higher levels of PMM. These results are confirmed by [18], who conclude that the higher levels of maturity are associated with higher levels of software quality as well as better IS project performance. Although there is a positive side, one cannot overlook the cost and complexity involved in maturing from one level to another [19. Organisations need to find the balance between the cost and complexity of maturing from one level to another versus the cost and schedule benefits of delivering IS projects.

The following research questions are posed based on the literature review:

a. What is the overall maturity level of IS projects within the South African context?

b. How do the South African IS PMM levels compare with international maturity levels?

c. Is there a direct correlation between IS PMM levels and IS project success?

These three research questions are answered through the research methodology used, as discussed in the next section.

\section{RESEARCH METHODOLOGY}

Research designs are concerned with turning the research question into a testing project 20. The research design can be either quantitative or qualitative. Quantitative research refers to the systematic empirical investigation of quantitative properties and phenomena and their relationships [21] 22]. The objective of quantitative research is to develop and employ mathematical models, theories and hypotheses pertaining to the phenomenon and possible relationships. The process of measurement is central to quantitative research because it provides the fundamental connection between empirical observation and mathematical expression of quantitative relationships.

The aim of this research is to investigate the maturity levels of IS projects and the possible correlation between maturity levels and project success over a decade and therefore a quantitative approach is thus more appropriate.

The PM Solutions Project Management Maturity Model was used as a baseline to develop the structured questionnaire [7]. This model is based on a two-dimensional framework. The first dimension reflects the maturity level i.e. the maturity levels of the CMMI. The second dimension depicts the key project management knowledge areas. Each of these nine knowledge areas' processes was converted into structured questions. These questions were mapped against the SEI maturity levels, implying that each process was measured against the maturity levels. Table ?? indicates the number of questions per knowledge area, resulting in a total of 62 questions for 2011 and 2013.

A structured questionnaire was used because it ensures that each respondent is presented with exactly the same questions in the same order. This ensures
Table 2: Number of questions per knowledge area

\begin{tabular}{|c|c|c|c|c|}
\hline & 2003 & 2007 & 2011 & 2013 \\
\hline $\begin{array}{l}\text { Integration manage- } \\
\text { ment }\end{array}$ & 3 & 9 & 7 & 7 \\
\hline Scope management & 5 & 6 & 8 & 8 \\
\hline Time management & 5 & 8 & 8 & 8 \\
\hline Cost management & 4 & 3 & 3 & 3 \\
\hline $\begin{array}{l}\text { Quality manage- } \\
\text { ment }\end{array}$ & 3 & 3 & 3 & 3 \\
\hline HR management & 3 & 7 & 7 & 7 \\
\hline $\begin{array}{l}\text { Communications } \\
\text { management }\end{array}$ & 4 & 6 & 8 & 8 \\
\hline Risk management & 6 & 11 & 11 & 11 \\
\hline $\begin{array}{l}\text { Procurement man- } \\
\text { agement }\end{array}$ & 6 & 6 & 7 & 7 \\
\hline $\begin{array}{l}\text { Total number of } \\
\text { questions }\end{array}$ & 39 & 59 & 62 & 62 \\
\hline
\end{tabular}

that answers can be reliably aggregated and that comparisons can be made with confidence between sample subgroups or between different survey periods.

Data collection depends on how much data a researcher plans to collect to draw sufficiently trustworthy conclusions. A dualistic approach was taken to gather responses, namely a web-based survey as well as a manually distributed survey. Both these approaches used the structured questionnaire as a basis. The webbased survey was open to IS/IT project managers of Project Management South Africa (PMSA), whereas the targeted survey focused on specific IS/IT project managers. In the second approach hard copies of the structured questionnaire were used and specifically targeted project managers were asked to complete the questionnaires manually. Table 3 shows the number of respondents that completed the questionnaire successfully over the four survey periods.

Table 3: Number of respondents per year

\begin{tabular}{|l|l|l|l|l|}
\hline Year & $\mathbf{2 0 0 3}$ & $\mathbf{2 0 0 7}$ & $\mathbf{2 0 1 1}$ & $\mathbf{2 0 1 3}$ \\
\hline No. of respondents & 820 & 220 & 1067 & 604 \\
\hline
\end{tabular}

Reliability is concerned about whether a research instrument can be interpreted consistently across different situations, whereas validity measures how well the survey measures what it is supposed to measure 23] 24. The following reliability checks were done on the structured questionnaires:

- Test-retest is relevant when a questionnaire is sampled with the same set of respondents at two different points in time [25]. In this longitudinal research, it was the fourth time the questionnaire was sampled and the results over the four sampling years were consistent.

- As scales were used in the questionnaire, internal consistency was very important to check. Internal consistency is a measure when assessing scales are used in the survey. Cronbach's alpha coefficient is a reflection of how well the different items complement one another in measuring the same variable 23. Cronbach's alpha coefficient was calculated for each of the knowledge areas for each of the four 
Table 4: Cronbach's alpha reliability tests

\begin{tabular}{|l|l|l|l|l|l|}
\hline & & $\mathbf{2 0 0 3}$ & $\mathbf{2 0 0 7}$ & $\mathbf{2 0 1 1}$ & $\mathbf{2 0 1 3}$ \\
\hline Integration management & Cronbach's alpha & 0.851 & 0.928 & 0.944 & 0.914 \\
& No. of items & 3 & 9 & 7 & 7 \\
\hline Scope management & Cronbach's alpha & 0.923 & 0.912 & 0.947 & 0.915 \\
& No. of items & 5 & 6 & 8 & 8 \\
\hline Time management & Cronbach's alpha & 0.923 & 0.937 & 0.959 & 0.872 \\
& No. of items & 5 & 8 & 8 & 8 \\
\hline Cost management & Cronbach's alpha & 0.920 & 0.909 & 0.936 & 0.891 \\
& No. of items & 4 & 3 & 3 & 3 \\
\hline Quality management & Cronbach's alpha & 0.930 & 0.918 & 0.947 & 0.909 \\
& No. of items & 3 & 3 & 3 & 3 \\
\hline HR management & Cronbach's alpha & 0.859 & 0.915 & 0.939 & 0.929 \\
& No. of items & 3 & 7 & 7 & 7 \\
\hline Communications management & Cronbach's alpha & 0.910 & 0.926 & 0.962 & 0.940 \\
& No. of items & 4 & 6 & 8 & 8 \\
\hline Risk management & Cronbach's alpha & 0.961 & 0.958 & 0.977 & 0.961 \\
& No. of items & 6 & 11 & 11 & 11 \\
\hline Procurement management & Cronbach's alpha & 0.948 & 0.938 & 0.960 & 0.892 \\
& No. of items & 6 & 6 & 7 & 7 \\
\hline
\end{tabular}

years and is presented in Table 4 Internal consistency levels of 0.7 or more are generally accepted as representing good reliability.

The results indicate that there is internal consistency throughout the longitudinal study.

The purpose of any questionnaire is that it measures what it intended to measure [26]. If a questionnaire does not measure what it is supposed to measure, then the conclusions and statistical analysis might also be invalid. Validity checks are available to verify that a questionnaire is suitable. The types of validity that can be used to assess a survey questionnaire are face, content, criterion and construct validity. The researcher opted for construct and content validity. Construct validity refers to the degree to which inferences can legitimately be made from the operationalisations in a study to the theoretical constructs on which those operationalisations were based. The questionnaire was constructed based on the IPM Solutions Project Management Maturity Model. This model, in turn, used the SEI's maturity model as well as the processes of the nine knowledge areas.

The results from this survey can be used with confidence as the reliability and validity of the questionnaire were proven through the reliability and validity tests.

\section{ANALYSIS OF RESULTS}

The results of the longitudinal analysis focus on two aspects, i.e. the maturity levels of IS projects over the period of study and the correlation between maturity levels and project success. The IS PMM investigates the overall maturity levels as well as the maturity levels per knowledge area.

\subsection{Information systems project management maturity}

The maturity levels for 2003, 2007, 2011 and 2013 are depicted in Fig. 1.

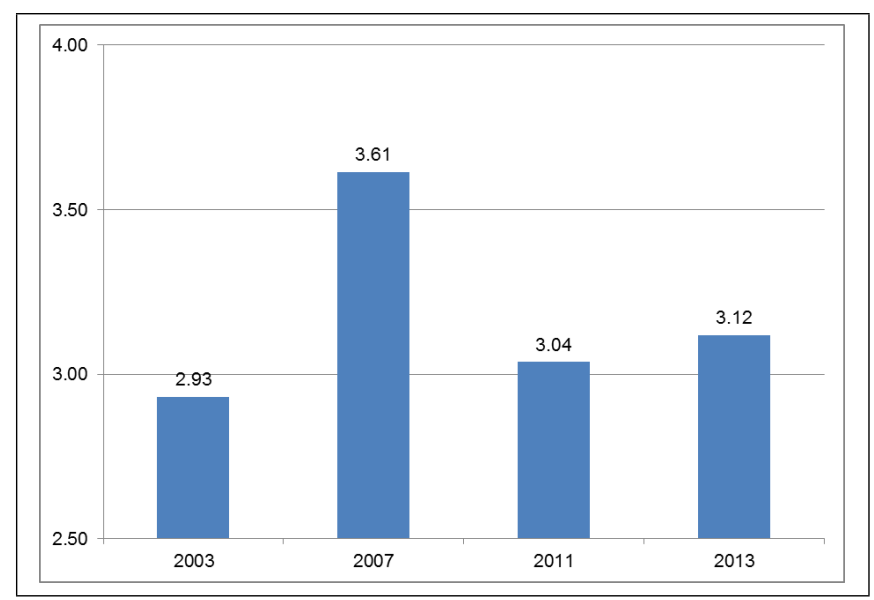

Figure 1: Maturity levels of IS projects

The results indicate that the maturity level averages around 3 for 2003 (maturity level = 2.93), 2011 (maturity level = 3.04) and 2013 (maturity level $=3.12$ ). The only exception is 2007 (maturity level $=3.61$ ). The results (excluding 2007) show a gradual improvement from 2.93 to 3.12 for the overall maturity level. Table 5 provides more insight into mean, standard deviation and skewness of the results. The results are once again more or less the same for all the years, especially when the skewness is considered. The skewness explains the gradual improvement of the maturity levels.

One aspect that is not explained by the data is the high maturity level of 3.61 for 2007. This high level might be attributed to the low number of responses for 2007 , i.e. only 220 versus the average of 830 for 
Table 5: Maturity level comparison between mean and standard deviation

\begin{tabular}{|l|l|l|l|l|}
\hline & $\mathbf{2 0 0 3}$ & $\mathbf{2 0 0 7}$ & $\mathbf{2 0 1 1}$ & $\mathbf{2 0 1 3}$ \\
\hline Mean & 2.92 & 3.61 & 3.04 & 3.12 \\
Std deviation & 0.852 & 0.751 & 0.881 & 0.880 \\
Skewness & 0.040 & -0.640 & -0.180 & -0.189 \\
\hline
\end{tabular}

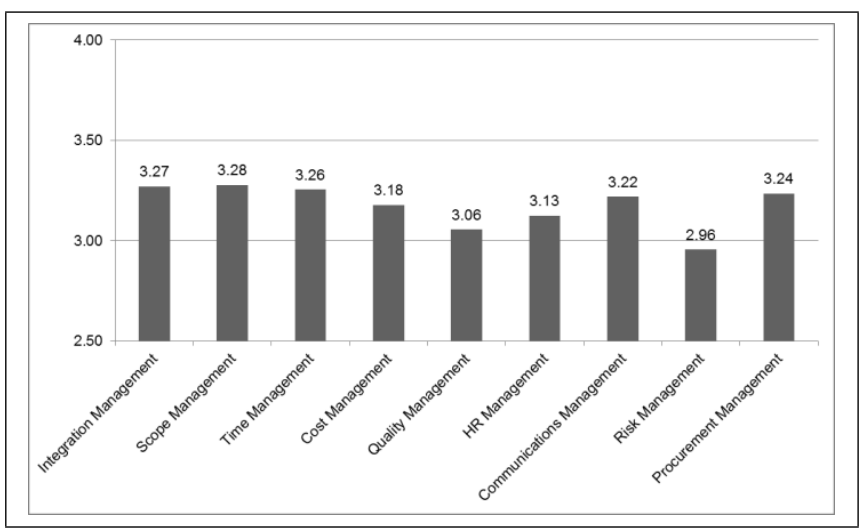

Figure 2: Maturity level per knowledge area

the other three years.

An in-depth analysis of the maturity of the nine knowledge areas highlights some interesting aspects. Fig. 2 shows the average maturity level for each of the nine knowledge areas for the four years that the research was done. The results indicate that for all practical purposes the maturity level for each of the knowledge areas is 3 . The average across the knowledge areas is 3.18 . The only knowledge area below the level of 3 is risk management (2.96).

This is in line with the findings of [6] where the maturity level of project risk management was also the lowest among all the knowledge areas, i.e. 2.75 for IS projects. Research undertaken by PricewaterhouseCoopers places general PMM at 2.5 [27. If the results from 2007 are omitted, then a different picture is painted as per Table 6 .

If the results of 2007 are excluded, then the maturity level of three of the knowledge areas drops below 3 , i.e. quality management $(3.06 \rightarrow 2.93)$, HR management $(3.13 \rightarrow 2.96)$ and risk management $(2.96 \rightarrow$ 2.82 ). The average maturity level also drops from 3.18 to 3.03 .

Fig. 3 depicts the average maturity level per year per knowledge area. The year-on-year comparison provides some interesting information.

If 2007 is excluded from the comparison, then it is clear that there is an improvement in the overall maturity per knowledge area. In most instances there was an improvement from 2003 to 2013. This, however, is not the case with quality and procurement management. Quality management improved from 2.87 to 3 and then dropped back to a maturity level of 2.97. It peaked in 2007 at a maturity level of 3.44. The data suggests that the maturity level of quality management strained to reach and go beyond the maturity level of 3 .

Procurement management is the other knowledge
Table 6: Comparison between maturity levels (excluding 2007)

\begin{tabular}{|l|l|l|}
\hline & $\begin{array}{l}\text { Including } \\
2007\end{array}$ & $\begin{array}{l}\text { Excluding } \\
2007\end{array}$ \\
\hline Integration management & 3.27 & 3.11 \\
Scope management & 3.28 & 3.13 \\
Time management & 3.26 & 3.08 \\
Cost management & 3.18 & 3.03 \\
Quality management & 3.06 & $\mathbf{2 . 9 3}$ \\
HR management & 3.13 & $\mathbf{2 . 9 6}$ \\
Communications manage- & 3.22 & 3.07 \\
ment & & \\
Risk management & $\mathbf{2 . 9 6}$ & $\mathbf{2 . 8 2}$ \\
Procurement manage- & 3.24 & 6 \\
ment & & \\
\hline Average & $\mathbf{3 . 1 8}$ & $\mathbf{3 . 0 3}$ \\
\hline
\end{tabular}

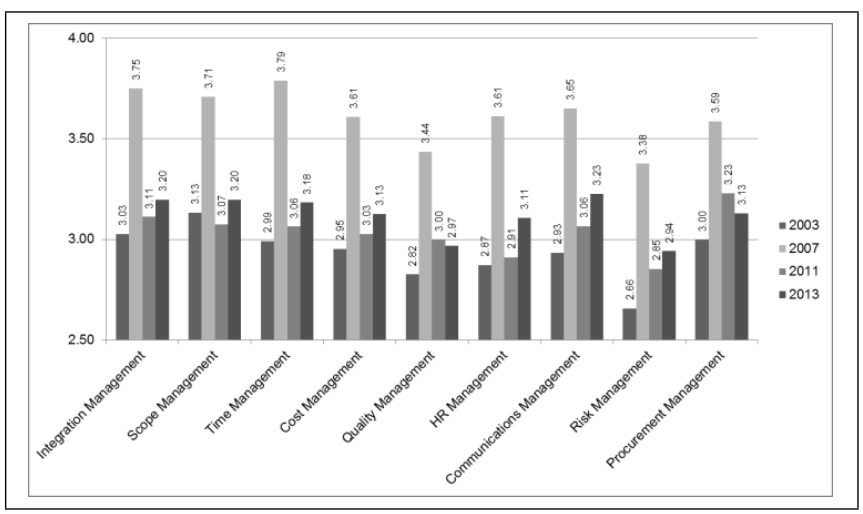

Figure 3: Maturity level per knowledge area per year

area that has a negative growth. The maturity level peaked at 3.59 in 2007 and then gradually dropped to 3.13 in 2013 . It must be noted that the overall maturity level has consistently been above 3 .

A knowledge area of concern is risk management. Although there is a year-on-year improvement, excluding 2007, the overall maturity level is still below the level of 3. Even the maturity level of 3.38 in 2007 is lower than those of the other knowledge areas in the same year.

It seems from the data that the two knowledge areas of concern are quality management and risk management. The other seven knowledge areas show some improvement but the average per knowledge area is still around the maturity level of 3 .

This section provided some insight into the maturity levels of the knowledge areas over a period of 10 years. It seems that there was no significant improvement from 2003 to 2013 in the average maturity level per knowledge area. The IS PMM in South Africa is on par with maturity levels in other international studies. The following section investigates the possible correlations between the maturity levels and project success.

\subsection{Project management maturity correlation with project success}

The first correlation is between the overall maturity level per year and project success. Table 7 presents 
Table 7: Correlation between overall maturity management and project success

\begin{tabular}{|l|l|l|l|l|}
\hline & $\mathbf{2 0 0 3}$ & $\mathbf{2 0 0 7}$ & $\mathbf{2 0 1 1}$ & $\mathbf{2 0 1 3}$ \\
\hline Pearson correlation & $0.094^{* *}$ & 0.08 & $0.211^{* *}$ & $0.207^{* *}$ \\
Sig. (2-tailed) & 0.008 & 0.28 & 0.00 & 0.001 \\
\hline
\end{tabular}

Table 8: Correlation between integration management maturity and project success

\begin{tabular}{|l|l|l|l|l|}
\hline & $\mathbf{2 0 0 3}$ & $\mathbf{2 0 0 7}$ & $\mathbf{2 0 1 1}$ & $\mathbf{2 0 1 3}$ \\
\hline Pearson correlation & $0.117^{* *}$ & 0.129 & $0.086^{*}$ & $0.204^{* *}$ \\
Sig. (2-tailed) & 0.00 & 0.072 & 0.013 & 0 \\
$N$ & 787 & 195 & 833 & 263 \\
\hline
\end{tabular}

the Pearson correlations.

The results in Table 7 indicate that there is a weak relationship between the two variables, i.e. PMM and project success. In the case of 2007 , there is actually no correlation. Although these relationships are weak, they are significant since the significant levels are below 0.5. The results do not provide a conclusive answer to whether there is correlation between project success and the overall maturity levels of the organisation. 27 found in their studies that "a higher project management maturity level will in most cases deliver superior performance in terms of overall project delivery and business benefits".

The correlations were divided up into each knowledge area to determine whether the maturity level of one specific knowledge area had a strong, significant impact on the success of the project.

\section{Project integration management (Table 8)}

The first correlation to investigate was project integration management. It is clear from the results that there are weak, significant correlations between the maturity level of integration management and project success apart from 2007.

\section{Project scope management (Table 9)}

Scope management is perceived as part of the triple constraint which determines project success, but as in the case of integration management, there is a weak but significant correlation between scope management maturity levels and project success. Once again, 2007 does not have any correlation between scope management maturity levels and project success as per Table 9 .

Table 9: Correlation between scope management maturity and project success

\begin{tabular}{|l|l|l|l|l|}
\hline & $\mathbf{2 0 0 3}$ & $\mathbf{2 0 0 7}$ & $\mathbf{2 0 1 1}$ & $\mathbf{2 0 1 3}$ \\
\hline Pearson correlation & $0.125^{* *}$ & 0.103 & $0.110^{* *}$ & $0.199^{* *}$ \\
Sig. (2-tailed) & 0.00 & 0.155 & 0.002 & 0 \\
$N$ & 790 & 190 & 834 & 264 \\
\hline \multirow{2*}{*}{ Correlation is significant at the 0.01 level (2-tailed). }
\end{tabular}

Project time management (Table 10)

As with scope management, time management is perceived as part of the triple constraint. Table 10 highlights that there is a weak but significant correlation between time management maturity levels and project success. Once again, 2007 does not indicate any significant correlations.

Table 10: Correlation between time management maturity and project success

\begin{tabular}{|l|l|l|l|l|}
\hline & $\mathbf{2 0 0 3}$ & $\mathbf{2 0 0 7}$ & $\mathbf{2 0 1 1}$ & $\mathbf{2 0 1 3}$ \\
\hline Pearson correlation & $0.080^{* *}$ & 0.068 & $0.086^{*}$ & $0.219^{* *}$ \\
Sig. (2-tailed) & 0.02 & 0.348 & 0.013 & 0 \\
$N$ & 790 & 194 & 831 & 263 \\
\hline
\end{tabular}

\section{Project cost management (Table 11)}

Cost management, the last knowledge area of the triple constraint, provides the same results as time and scope management. The results are depicted in Table 11 .

Table 11: Correlation between cost management maturity and project success

\begin{tabular}{|l|l|l|l|l|}
\hline & $\mathbf{2 0 0 3}$ & $\mathbf{2 0 0 7}$ & $\mathbf{2 0 1 1}$ & $\mathbf{2 0 1 3}$ \\
\hline Pearson correlation & $0.097^{* *}$ & 0.072 & $0.087^{*}$ & $0.162^{* *}$ \\
Sig. (2-tailed) & 0.01 & 0.323 & 0.013 & 0 \\
$N$ & 775 & 190 & 822 & 257 \\
\hline
\end{tabular}

\section{Project quality management (Table 12)}

This is the first knowledge area where there is some deviation from the previous knowledge areas. 2003 and 2013 show a weak but significant correlation between the maturity level of quality management and project success. 2007 and 2011, however, show no correlation at all as per Table 12

Table 12: Correlation between quality management maturity and project success

\begin{tabular}{|l|l|l|l|l|}
\hline & $\mathbf{2 0 0 3}$ & $\mathbf{2 0 0 7}$ & $\mathbf{2 0 1 1}$ & $\mathbf{2 0 1 3}$ \\
\hline Pearson correlation & $0.110^{* *}$ & 0.088 & $0.035^{*}$ & $0.197^{* *}$ \\
Sig. (2-tailed) & 0.00 & 0.234 & 0.317 & 0 \\
$N$ & 778 & 186 & 832 & 263 \\
\hline
\end{tabular}

\section{Project HR management (Table 13)}

2007 shows a quite peculiar correlation. The correlation $(\mathrm{r}=-0.004, \mathrm{n}=191, \mathrm{p}=0.962)$ is suddenly negative but the Pearson correlation indicates that this can be ignored. 2003, 2011 and 2013 show a weak but significant correlation between the maturity level of HR management and project success. 
Table 13: Correlation between HR management maturity and project success

\begin{tabular}{|l|l|l|l|l|}
\hline & $\mathbf{2 0 0 3}$ & $\mathbf{2 0 0 7}$ & $\mathbf{2 0 1 1}$ & $\mathbf{2 0 1 3}$ \\
\hline Pearson correlation & $0.074^{*}$ & -0.004 & $0.085^{*}$ & $0.195^{* *}$ \\
Sig. (2-tailed) & 0.04 & 0.0962 & 0.014 & 0 \\
$N$ & 777 & 191 & 832 & 262 \\
\hline
\end{tabular}

Project communication management (Table 14)

Communication has been found to be one of the factors contributing to project success [1] 2]. The results over the last 10 years challenge this finding. Only 2011 and 2013 provide a weak but significant correlation between the maturity level of communication management and project success.

Table 14: Correlation between communication management maturity and project success

\begin{tabular}{|l|l|l|l|l|}
\hline & $\mathbf{2 0 0 3}$ & $\mathbf{2 0 0 7}$ & $\mathbf{2 0 1 1}$ & $\mathbf{2 0 1 3}$ \\
\hline Pearson correlation & 0.044 & 0.137 & $0.087^{*}$ & $0.158^{*}$ \\
Sig. (2-tailed) & 0.22 & 0.061 & 0.012 & 0 \\
$N$ & 787 & 189 & 833 & 261 \\
\hline
\end{tabular}

\section{Project risk management (Table 15)}

Given the fact that risk management is continuously ranked as the knowledge area with the lowest maturity level as per Figs. 2 and 4, it comes as no surprise that only 2013 indicates some correlation between the maturity level of risk management and project success. This correlation is, however, weak $(\mathrm{r}=0.154, \mathrm{n}=261$, $\mathrm{p}=0)$.

Table 15: Correlation between risk management maturity and project success

\begin{tabular}{|l|l|l|l|l|}
\hline & $\mathbf{2 0 0 3}$ & $\mathbf{2 0 0 7}$ & $\mathbf{2 0 1 1}$ & $\mathbf{2 0 1 3}$ \\
\hline Pearson correlation & 0.056 & 0.120 & 0.021 & $0.154^{*}$ \\
Sig. (2-tailed) & 0.12 & 0.099 & 0.554 & 0 \\
$N$ & 775 & 190 & 830 & 261 \\
\hline
\end{tabular}

\section{Project procurement management (Table 16)}

The last knowledge area, procurement management, shows the same tendency as quality management, i.e. only 2003 and 2013 show some correlation. Once again, the correlations are weak but significant as per Table 16

Given the fact that none of these correlations was indicated as strong and significant, exploratory factor analysis (EFA) was embarked on. The purpose of the EFA was to determine whether some of the processes within knowledge areas could be excluded. The rationale was that the omission of some processes would create a stronger correlation between the knowledge area and project success.
Table 16: Correlation between procurement management maturity and project success

\begin{tabular}{|l|l|l|l|l|}
\hline & $\mathbf{2 0 0 3}$ & $\mathbf{2 0 0 7}$ & $\mathbf{2 0 1 1}$ & $\mathbf{2 0 1 3}$ \\
\hline Pearson correlation & $0.088^{*}$ & 0.009 & 0.060 & $0.144^{*}$ \\
Sig. (2-tailed) & 0.02 & 0.900 & 0.089 & 0 \\
$N$ & 725 & 192 & 807 & 247 \\
\hline
\end{tabular}

The EFA suggested that seven knowledge areas across the four years could be subjected to further factor analysis. This means that only $19 \%$ of the 36 knowledge areas ( 7 knowledge areas over 4 years) were subjected to further factor analysis.

An eigenvalue of 0.7 was used instead of the normal value of 1 . The rationale was that the value of 1 is too strict and that the results can sometimes be dramatic 28 .

A maximum likelihood factor analysis was conducted on each of the items for each of the knowledge areas for every year of the study with oblique rotation (Promax with Kaiser normalisation). Refer to Table 4 for the number of items per knowledge area per year. The Kaiser-Meyer-Olkin (KMO) measure verified the sampling adequacy for the analysis as per Table 17

Table 17: KMO measures

\begin{tabular}{|l|l|l|l|l|}
\hline & $\mathbf{2 0 0 3}$ & $\mathbf{2 0 0 7}$ & $\mathbf{2 0 1 1}$ & $\mathbf{2 0 1 3}$ \\
\hline Integration manage- & 0.729 & 0.905 & 0.931 & 0.904 \\
ment & & & & \\
Time management & 0.887 & 0.871 & 0.930 & 0.913 \\
Cost management & 0.844 & 0.738 & 0.755 & 0.747 \\
Quality management & 0.761 & 0.729 & 0.770 & 0.742 \\
HR management & 0.720 & 0.875 & 0.906 & 0.907 \\
Comms management & 0.827 & 0.888 & 0.941 & 0.927 \\
Risk management & 0.912 & 0.944 & 0.961 & 0.946 \\
Procurement manage- & 0.898 & 0.881 & 0.931 & 0.904 \\
ment & * Correlation is significant at the 0.05 level (2-tailed).
\end{tabular}

KMO values closer to 1 indicate that patterns of correlations are relatively compact and that factor analysis should yield distinct and reliable factors [23]. The values in Table 17 show that factor analysis should yield distinct and reliable factors.

An initial analysis was run to obtain eigenvalues for each factor in each of the four data sets. Of the 36 knowledge areas, only 7 knowledge areas had factors with eigenvalues higher than 0.7. It must be noted that the data from 2003 and 2011 did not provide any eigenvalues higher than 0.7 . These results are displayed in Table 18 to 23.

Two factors were identified and cumulatively explained $78.51 \%$ of the variance. 
Table 18: Eigenvalues for project integration management 2007

\begin{tabular}{|l|l|l|l|}
\hline Factor & Total & \% of variance & Cumulative \% \\
\hline 1 & 5.747 & 63.853 & 63.583 \\
2 & 0.861 & 9.563 & 73.415 \\
3 & 0.587 & 6.523 & 79.938 \\
4 & 0.425 & 4.720 & 84.659 \\
5 & 0.422 & 4.684 & 89.343 \\
6 & 0.312 & 3.466 & 92.808 \\
7 & 0.256 & 2.844 & 95.652 \\
8 & 0.215 & 2.394 & 98.046 \\
9 & 0.176 & 1.954 & 100.000 \\
\hline
\end{tabular}

Table 19: Eigenvalues for project time management 2007

\begin{tabular}{|l|l|l|l|}
\hline Factor & Total & \% of variance & Cumulative \% \\
\hline 1 & 5.576 & 69.699 & 69.699 \\
2 & 0.705 & 8.814 & 78.513 \\
3 & 0.435 & 5.436 & 83.949 \\
4 & 0.358 & 4.469 & 88.418 \\
5 & 0.304 & 3.795 & 92.213 \\
6 & 0.257 & 3.216 & 95.428 \\
7 & 0.230 & 2.877 & 98.305 \\
8 & 0.136 & 1.695 & 100.000 \\
\hline
\end{tabular}

Table 20: Eigenvalues for project human resource management 2007

\begin{tabular}{|l|l|l|l|}
\hline Factor & Total & \% of variance & Cumulative $\%$ \\
\hline 1 & 4.639 & 66.266 & 66.266 \\
2 & 0.712 & 10.172 & 76.438 \\
3 & 0.526 & 7.510 & 83.948 \\
4 & 0.362 & 5.172 & 89.120 \\
5 & 0.335 & 4.781 & 93.901 \\
6 & 0.238 & 3.407 & 97.308 \\
7 & 0.188 & 2.692 & 100.000 \\
\hline
\end{tabular}

Table 21: Eigenvalues for project scope management 2007

\begin{tabular}{|l|l|l|l|}
\hline Factor & Total & \% of variance & Cumulative \% \\
\hline 1 & 5.040 & 63.000 & 63.000 \\
2 & 0.744 & 9.297 & 72.297 \\
3 & 0.546 & 6.825 & 79.122 \\
4 & 0.397 & 4.963 & 84.085 \\
5 & 0.377 & 4.712 & 88.797 \\
6 & 0.336 & 4.203 & 93.000 \\
7 & 0.316 & 3.947 & 96.947 \\
8 & 0.244 & 3.053 & 100.000 \\
\hline
\end{tabular}

Table 22: Eigenvalues for project time management 2007

\begin{tabular}{|l|l|l|l|}
\hline Factor & Total & \% of variance & Cumulative \% \\
\hline 1 & 5.012 & 62.655 & 62.655 \\
2 & 0.835 & 10.433 & 73.088 \\
3 & 0.507 & 6.336 & 79.424 \\
4 & 0.473 & 5.908 & 85.333 \\
5 & 0.356 & 4.453 & 89.786 \\
6 & 0.343 & 4.282 & 94.067 \\
7 & 0.264 & 3.299 & 97.367 \\
8 & 0.211 & 2.633 & 100.000 \\
\hline
\end{tabular}

Table 23: Eigenvalues for project communication management 2007

\begin{tabular}{|l|l|l|l|}
\hline Factor & Total & \% of variance & Cumulative $\%$ \\
\hline 1 & 5.651 & 70.632 & 70.632 \\
2 & 0.731 & 9.133 & 79.766 \\
3 & 0.398 & 4.969 & 84.735 \\
4 & 0.295 & 3.687 & 88.421 \\
5 & 0.262 & 3.271 & 91.692 \\
6 & 0.252 & 3.147 & 94.839 \\
7 & 0.229 & 2.859 & 97.698 \\
8 & 0.184 & 2.302 & 100.000 \\
\hline
\end{tabular}

Table 24: Eigenvalues for project procurement management 2007

\begin{tabular}{|l|l|l|l|}
\hline Factor & Total & \% of variance & Cumulative \% \\
\hline 1 & 4.491 & 64.150 & 64.150 \\
2 & 0.754 & 10.768 & 74.918 \\
3 & 0.505 & 7.211 & 82.129 \\
4 & 0.415 & 5.934 & 88.063 \\
5 & 0.301 & 4.306 & 92.369 \\
6 & 0.281 & 4.011 & 96.380 \\
7 & 0.253 & 3.620 & 100.000 \\
\hline
\end{tabular}


For each of the seven knowledge areas, the following process was followed:

a. The items for each factor were identified.

b. Confirmatory factor analysis was once again run on the items which were part of the factors.

c. The reliability for each of the factors was tested again using Cronbach's alpha.

d. If the reliability was higher than 0.7 , then a correlation was determined between the new items for each factor and project success.

e. This new correlation was compared with the original correlations to determine whether the omission of certain items would strengthen the correlation between the specific knowledge area and project success.

The final results are displayed in Table 25 and show that there is no major difference between the correlations before and after factor analysis.

Given the results in Table 25, it can be concluded that the original data and processes can be used as there is minimal change between the correlations and significance.

\section{DISCUSSION}

The longitudinal analysis over a decade of IS PMM levels reveals some interesting and peculiar results. The results for 2007 are clearly an outlier and influence the results in a positive way. The results for 2003, 2011 and 2013 are more in line with one another.

The average maturity level hovers around 3 . This implies that most IS projects are functioning at a level where the processes are defined and that projects are using approved processes. There is a slight but steady increase from 2003 to 2013 as per Fig. 1. The increase is 0.19 over a decade, which is actually negligible. 2003 is the only year where the average maturity level is below 3 and 2007 shows a spike to a level of 3.61 .

The average of IS PMM levels per knowledge area reveals that project risk management is the only knowledge area below 3 (average $=2.96$ ). The maturity levels of the other eight knowledge areas are between 3 and 3.5 , revealing that there is not a vast difference between these maturity levels. If the results of 2007 are ignored, then there are three knowledge areas with maturity levels below 3, i.e. quality, HR and risk management.

The year-on-year analysis of the maturity level of each knowledge area highlights that there is an improvement in most instances. The results in Fig. 3 show that seven of the nine knowledge areas show an increase. This increase is only if the results of 2007 are ignored. The increases are insignificant, however, ranging from 0.07 (scope management) to 0.3 (communications management). Quality and procurement are the two knowledge areas where there is some fluctuation between the maturity levels over the period of study. Both these knowledge areas saw a drop in maturity levels in 2013 but these are still higher than in 2003.

Quality management is one of the knowledge areas forming part of the quadruple constraint and it is quite surprising that the average maturity level for it is below 3 (2.93 excluding 2007). South African IS project managers perceive the quadruple constraint as the factor that contributes the most to project success [1. This discrepancy needs to be investigated further. The correlations between the maturity levels of the various knowledge areas and project success reveal some interesting facts. There are no significant correlations for 2007 amongst any of the knowledge areas, be they positive or negative. This raises the question once again why there is a difference in the results of 2007. The correlations of 2003, 2011 and 2013 provide some insight. In most instances the correlations are weak but significant. The correlations indicate that for most of the knowledge areas there is at least one weak, significant correlation but also two to three weak, significant correlations. Fig. 4 is a graphical depiction of these weak, significant correlations.

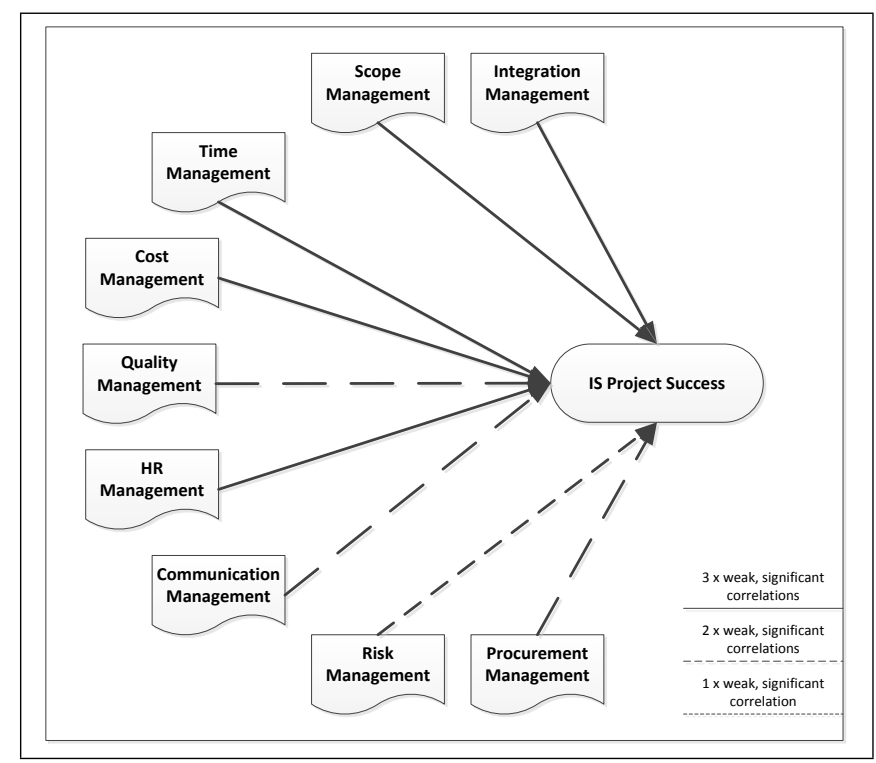

Figure 4: Correlation between knowledge areas and IS project success

Over the last decade five knowledge areas have proved to have a positive weak but significant influence on IS project success, i.e. integration, scope, time, cost and HR management. Scope, time and cost management form the triple constraint and it is quite refreshing to confirm once again that these three knowledge areas are perceived to contribute to IS project success. If integration management is also included in the equation, then it can be deduced that the core knowledge areas contribute to project success, even though the correlations are weak but significant.

Quality, communication and procurement management have positive and significant correlations for two of the three years excluding 2007. Quality and procurement management have weak, significant correlations in 2003 and 2013. In the case of quality management, the maturity level improved from 2.82 (2003) to 2.97 (2013). The maturity level of procurement management improved from 3 (2007) to 3.13 (2013). It can be deduced from the results that if there is an improvement in the maturity level, then the correlation 
Table 25: Comparison of correlation values

\begin{tabular}{|c|c|c|c|c|c|c|c|}
\hline & & \multicolumn{3}{|c|}{ Original Correlation Values } & \multicolumn{3}{|c|}{ Adjusted Correlation Values } \\
\hline & & Pearson & Sig. (2-tailed) & $N$ & Pearson & Sig. (2-tailed) & $N$ \\
\hline \multirow[t]{3}{*}{2007} & Integration & 0.129 & 0.072 & 195 & 0.118 & 0.103 & 192 \\
\hline & Time & 0.068 & 0.348 & 194 & -0.026 & 0.717 & 191 \\
\hline & $\mathrm{HR}$ & -0.004 & 0.962 & 191 & 0.048 & 0.510 & 192 \\
\hline \multirow[t]{4}{*}{2013} & Scope & $0.199^{* *}$ & 0 & 264 & $0.190^{* *}$ & 0.002 & 264 \\
\hline & Time & $0.219^{* *}$ & 0 & 263 & $0.226^{* *}$ & 0 & 263 \\
\hline & Communication & $0.158^{* *}$ & 0 & 261 & $0.151^{* *}$ & 0.014 & 261 \\
\hline & Procurement & $0.144^{*}$ & 0 & 247 & $0.145^{*}$ & 0.023 & 246 \\
\hline
\end{tabular}

Table 26: Reflection between maturity level improvement and correlation improvement

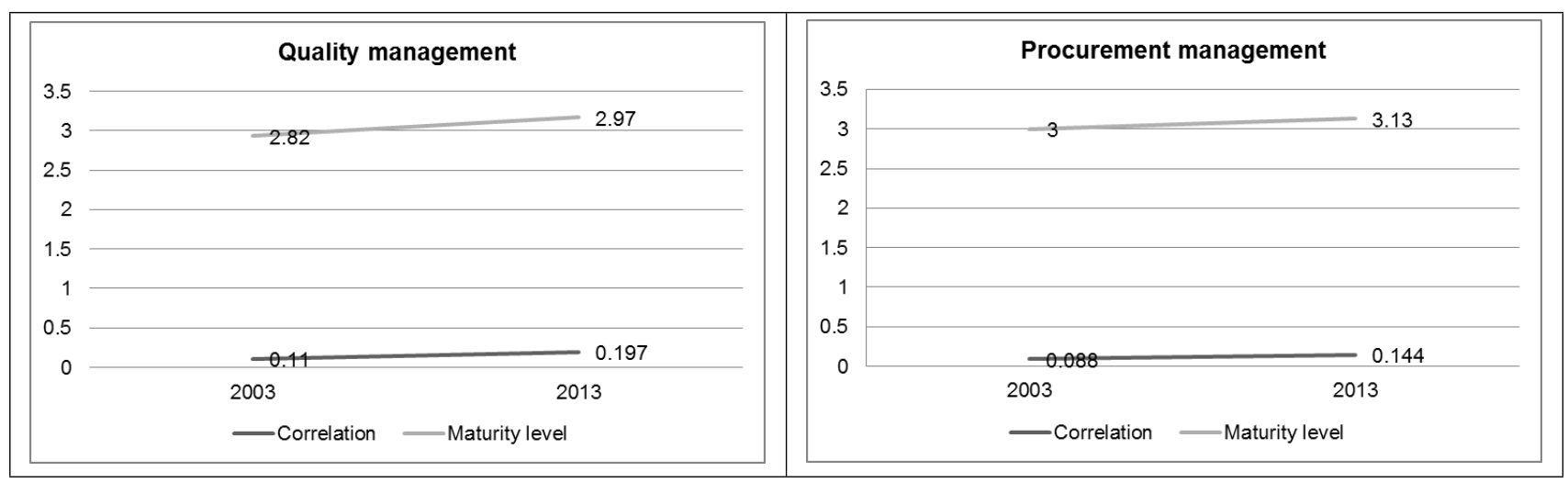

between the maturity level of the knowledge area and project success is increasing.

Table 26 is a graphical presentation of this analysis.

The same conclusion can also be drawn for communications management. There are weak, significant correlations between the maturity level and project success. This is for 2011 and 2013. As with quality and procurement management, once the maturity level increases, the correlation becomes stronger. The maturity level increased from 3 to 3.13 and the correlation increased from 0.087 to 0.158 .

Risk management is the only knowledge area where only one of the four studies indicates a weak, significant correlation, i.e. 2013. No correlations could be found for 2003, 2007 and 2011. It must be noted that no analysis of the data was done to determine whether there is a correlation between risk management maturity levels and the number of projects that are failing.

Fig. 4 highlights another important aspect. It appears that the respondents paid more attention to the core knowledge areas and that the facilitating knowledge areas were not perceived as that important. If the maturity levels of the facilitating knowledge areas are improved, then the overall success of IS projects will increase.

\section{CONCLUSIONS}

Organisational maturity and specifically project management maturity have come a long way. The purpose of maturity is to improve on the processes themselves and, through these improvements, ensure the success of the project and ultimately the organisation. The literature review reveals that there are various PMM models in place that can be used to improve the maturity of the project management processes. Although PMM emerged from software engineering, there is not an IS-specific maturity model. IS projects need to mature the same as any other type of project. Organisations need to employ other IS-specific frameworks and standards to address the IS component of projects. Control Objectives for Information and Related Technology (COBIT), the Capability Maturity Model Integration (CMMI) and the Information Technology Infrastructure Library (ITIL) come to mind. The literature highlights the benefit of maturing and suggests that the higher the maturity levels, the better the project success rate.

The results of the longitudinal study are not very comforting. Over a period of 10 years, maturity levels have not improved beyond 3, which indicates that processes are defined. There are also specific knowledge areas that are of concern such as risk management, which continues to be below the level of 3 . On the other hand, the results of the study are in line with other international studies. These studies also show that the maturity levels of IS projects are around 3 . An in-depth analysis of the data could not establish beyond reasonable doubt a strong significant correlation between maturity levels and project success. The results suggest that a higher maturity level enhances overall project performance. It must be noted that the projects were evaluated in isolation and not as part of an overall project portfolio. Evaluating the success of 
the overall portfolio might yield different results and other insight with regard to IS PMM.

It is nevertheless recommended that organisations embark on a journey of improving the IS PMM levels. Although the results are not strongly favourable, there is a suggestion that the success of IS projects can be attributed to the maturity of the various knowledge area processes. Special care and focus should be given to the core knowledge areas that do show some weak, significant correlations. Problem knowledge areas such as risk management also need some special attention to understand the processes and ways to improve the maturity levels of these knowledge areas.

This research highlights that although there are various research and official project management maturity models in place, the overall PMM levels are not improving. This is the case internationally as well as locally in South Africa. The reason for this phenomenon needs to be unearthed and this will form part of future research. Future research will also investigate the correlations of PMM on failed and challenged projects. It might be of interest to investigate whether PMM levels have an influence on minimising project failure. In other words, maturity levels might not ensure project success but may minimise project failure.

Given all the maturity models and research into PMM and specifically IS PMM, the question still stands: to mature or not to mature?

\section{REFERENCES}

[1] C. Marnewick. "A longitudinal analysis of ICT project success". In Proceedings of the South African Institute for Computer Scientists and Information Technologists Conference, pp. 326-334. ACM, 2012.

[2] C. Marnewick and L. Labuschagne. "Factors that influence the outcome of information technology projects in South Africa: An empirical investigation". Acta Commercii, vol. 9, no. 1, pp. 78-89, 2009.

[3] T. J. Cooke-Davies and A. Arzymanow. "The maturity of project management in different industries: An investigation into variations between project management models". International Journal of Project Management, vol. 21, no. 6, pp. 471-478, 2003.

[4] G. Jia, Y. Chen, X. Xue, J. Chen, J. Cao and K. Tang. "Program management organization maturity integrated model for mega construction programs in China". International Journal of Project Management, vol. 29, no. 7, pp. 834-845, 2011.

[5] K. Jugdev and J. Thomas. "Project management maturity models: The silver bullets of competitive advantage." Project Management Journal, vol. 33, no. 4, pp. 4-14, 2002.

[6] C. W. Ibbs and Y. H. Kwak. "Assessing project management maturity". Project Management Journal, vol. 31, no. 1, pp. 32-43, 2000.

[7] J. S. Pennypacker and K. P. Grant. "Project management maturity: An industry benchmark". Project Management Journal, vol. 34, no. 1, pp. 4-11, 2003.

[8] B. Pasian, S. Sankaran and S. Boydell. "Project management maturity: a critical analysis of existing and emergent factors". International Journal of Managing Projects in Business, vol. 5, no. 1, pp. 146-157, 2012.

[9] S. Pretorius, H. Steyn and J. Jordaan. "Project management maturity and project management success in the engineering and construction industries in Southern Africa". South African Journal of Industrial Engineering, vol. 23, no. 3, pp. 1-12, 2012.

[10] C. Marnewick. "To invest or not to invest in SADC-a project management perspective". Journal of Contemporary Management, vol. 9, pp. 341-363, 2012.

[11] P. M. Institute. Organizational Project Management Maturity Model (OPM3). Project Management Institute, 3rd ed. edn., 2012.

[12] R. Sowden (editor). Portfolio, Programme and Project Management Maturity Model (P3M3). Office of Government Commerce, London, UK, 2010.

[13] M. B. Chrissis, M. Konrad and S. Shrum. CMMI for development: guidelines for process integration and product improvement. Pearson Education, 2011.

[14] E. S. Andersen and S. A. Jessen. "Project maturity in organisations". International journal of project management, vol. 21, no. 6, pp. 457-461, 2003.

[15] D. Milosevic and A. Ozbay. "Drivers of project delivery capability: an empirical study". In Management of Engineering and Technology, 2001. PICMET'01. Portland International Conference on, pp. 553-561. IEEE, 2001.

[16] C. Marnewick and L. Labuschagne. "A conceptual framework to improve the project delivery capability within an organisation". Acta Commercii, vol. 10, pp. 249-263, 2010.

[17] Y. H. Kwak and C. W. Ibbs. "Calculating project management's return on investment". Project Management Journal, vol. 31, no. 2, pp. 38-47, 2000.

[18] G. H. Subramanian, J. J. Jiang and G. Klein. "Software quality and IS project performance improvements from software development process maturity and IS implementation strategies". Journal of Systems and Software, vol. 80, no. 4, pp. 616-627, 2007.

[19] H. Saiedian and R. Kuzara. "SEI capability maturity model's impact on contractors". Computer, vol. 28, no. 1, pp. 16-26, 1995.

[20] G. Thomas. How to do your research project: a guide for students in education and applied social sciences. Sage, 2009.

[21] M. Balnaves and P. Caputi. Introduction to quantitative research methods: An investigative approach. Sage, 2001.

[22] N. Blaikie. Analyzing quantitative data: From description to explanation. Sage, 2003.

[23] A. Field. Discovering statistics using IBM SPSS statistics. Sage, 2013.

[24] D. Byrne. Interpreting quantitative data. Sage, 2002.

[25] B. Kitchenham and S. L. Pfleeger. "Principles of survey research part 4: questionnaire evaluation". SIGSOFT Softw. Eng. Notes, vol. 27, no. 3, pp. 20-23, May 2002. ISSN 0163-5948. doi:10.1145/638574.638580. URL http://doi.acm .org/10.1145/638574.638580.

[26] S. Cameron and D. Price. Business Research Methods: A Practical Approach. McGraw Hill, 2009. 
[27] PriceWaterhouseCoopers. Boosting business performance through programme and project management. PriceWaterhouseCoopers, 2004.

[28] I. Jolliffe. "Discarding variables in a principal component analysis. I: Artificial data". Applied statistics, pp. 160-173, 1972. 